\title{
Grand challenges in evolutionary developmental biology
}

\author{
Alessandro Minelli* \\ Department of Biology, University of Padova, Padova, Italy \\ ${ }^{*}$ Correspondence: alessandro.minelli@unipd.it \\ Edited by: \\ Armin P. Moczek, Indiana University, USA \\ Reviewed by: \\ Mark E. Olson, Universidad Nacional Autónoma de México, Mexico
}

Keywords: internalized polyphenism, temporal and spatial boundaries of development, evolution of the developmental role of epigenetic mechanisms, exaptation of developmental processes, saltational evolution, evolutionary transitions, paramorphism

\section{EVO-DEVO'S IDENTITY}

There is a widespread consensus on the view that evolutionary developmental biology (evo-devo) is the discipline eventually borne to fill the gap between evolutionary biology and developmental biology, following a divorce between these two fields that extended over more than half a century (Amundson, 2005). On closer inspection, however, this broadly acceptable perspective discloses a wealth of questions, if looked at retrospectively, and of potentially divergent possibilities, if looked at prospectively.

The slow pace of integration between the different threads that were converging into evo-devo was well expressed by Raff (2000) in a survey of the main issues in this field. Some 15 years ago Raff, one of the discipline's founding fathers, remarked that "What constitutes the fundamental problems for a science of evolutionary developmental biology (evo-devo) depends on whether the scientist is a developmental biologist, a paleontologist or an evolutionary biologist" and drafted a list of at the time hot issues. Evo-devo has answered these questions only in part. However, this discipline is now mature for addressing a number of more precise, and more challenging questions, as I will argue in this article.

To date, two sets of problems have been primarily floated in discussions about the identity and research targets of evo-devo. On the one hand are those centered around the (controversial) notions of evolvability, robustness and constraint in connection with the increasing appreciation of the intricacies of the genotype $\rightarrow$ phenotype map (Alberch, 1991; Altenberg, 1995; West-Eberhard,
2003; Pigliucci, 2010; Wagner and Zhang, 2011). On the other hand are those centered around the notions of origination, innovation, and novelty, the so-called "innovation triad." To Hendrikse et al. (2007), for example, evolvability is the key issue that justifies recognizing evo-devo as an autonomous discipline. Others, e.g., Müller and Newman (2005), focus instead on the innovation triad.

Unfortunately, for all these candidates to core concept of evo-devo, too many alternative definitions have been proposed (or, more dangerously, implicitly assumed), thus adding new items to the dramatically increasing series of biological terms on whose definition there seem to be more and more disagreement. Eventually, we should probably learn to accept that multiple notions associated with each of these terms deserve to be retained and perhaps recognized by adjectival specifications. Similar terminological refinement is applied to other biological terms such as species (e.g., Claridge et al., 1997), homology (e.g., Minelli and Fusco, 2013a), and gene (e.g., Beurton et al., 2000). In discussing the concept of gene in historical perspective, Müller-Wille and Rheinberger (2009) have sensibly recalled Friedrich Nietzsche's (1887; second essay, para. 13) dictum, that "all concepts in which an entire process is semiotically concentrated elude definition; only that which has no history is definable."

In addition to terminological ambiguity, there is an another problem with the "innovation triad" - the problem that these terms are all framed in terms of "origins." Framing definitions in terms of origin requires splitting the evolutionary sequence in two contiguous segments, "before" and "after" the origination of a new feature. This splitting is a natural consequence if origination indeed "refers to the specific causality of the generative conditions that underlie both the first origins and the later innovations of phenotypes" and especially "the very first beginnings of phenotypes, e.g., the origin of multicellular assemblies, of complex tissues, and of the generic forms that result from the self-organizational and physical principles of cell interaction (Newman, 1992, 1994). In contrast, innovation [evolutionary modes and mechanisms] and novelty [their phenotypic outcome] designate the processes and results of introducing new characters into already existing phenotypic themes of a certain architecture (bodyplans)" (Müller and Newman, 2005, p. 490). This separation, however, is artificial. The better we know a process, the less we are able to identify its exact origins, these instead being determined by arbitrary choice. In science, and especially in biological disciplines with a strong historical dimension such as evolutionary biology and developmental biology, we should frame questions in terms of transitions rather than origins.

\section{BROADENING THE SCOPE OF THE DISCIPLINE}

We can hardly hope to get meaningful and interesting results from a study of systems whose boundaries we have not meaningfully fixed. Fixing boundaries means justifying which set of objects to include in the system we describe or experiment on, or to exclude from it, and why; and also which temporal boundaries we regard as sensible starting and end points for our observations. This concern is critically important 
in evo-devo, due to the concept of development that usually underlies the approach and thus the determination of the problems we address. Most of evo-devo, in particular most of those studies that are based on comparative developmental genetics, implicitly or explicitly take for granted that development is a sequence of changes through which an adult multicellular animal or plant is produced, through increasingly complex stages, starting from a single cell which is usually a fertilized egg. But this concept is seriously inadequate. Development is not limited to multicellulars, and in these a developmental sequence does not necessarily begins with an egg, fertilized or not. It does not necessarily lead to the production of a conventional adult, nor does it necessarily involve a steady increase in complexity (Minelli, 2011, 2014).

Another point to be revisited is the taxonomic coverage of evo-devo. We need urgently to expand work beyond metazoans. As a consequence of comparative and experimental evidence primarily based on animals, our whole perspective on development and its evolution is strongly biased: generalizations can not necessarily be extrapolated from the animal kingdom to the other kingdoms. Still worse, the taxonomic bias acts as a strong constraint on the formulation of the questions addressed by researchers. Who cares, for examples, for the ways biological form can emerge from systems made of entangled masses of virtually onedimensional threads which grow from one of the tips and apparently have very limited possibility to send signals to their neighbors? To be sure, the evolution of morphogenetic processes in fungi will never be addressed in so far as we are only concerned with animals and plants. Plants are also much less in the focus of evo-devo, in respect to animals. Moreover, up to now evo-devo has not yet really extended to the green algae, within which an astonishing diversity of structural plans has developed, including those based on syncytial rather than cellular organization.

To be sure, the list of desired groups could continue the whole length of this article. I will keep it short, but not before stressing that this list of taxa would easily turn into a list of new challenging questions. For example, among the haplodiplobiont organisms, there are those, such as some Ectocarpus species among the brown algae, in which the haploid gametophyte and the diploid sporophyte are morphologically as much as identical, whereas the gametophyte prevails in mosses, and the sporophyte in the flowering plants. A comparison of these three systems would hopefully help unravel the nature and history of the correlations between ploidy and whole body organization. Haplodiplobionts, by the way, show also most distinctly that a single life cycle may include more than one generation and thus more than one developmental sequence-a condition that however applies also to diplobionts, if we regard their gametogenesis as an independent developmental sequence (Minelli, 2014). I close this plea for a radically extended taxonomic coverage by evo-devo by mentioning unicellulars, among which developmental processes are often dramatic, as in the case of trypanosomes.

A third point is the choice of socalled model organisms. There has been much debate about the best criteria for adding new items to the select list of model species, but none of them seems to pass rigorous logical scrutiny (discussed in Jenner, 2006; Minelli and Baedke, 2014). Empirically, "random walks" to explore closer or increasingly distant relatives of the most fashionable model species have regularly revealed the idiosyncrasies of the model, most unexpectedly among morphologically conservative animals such as nematodes. For example, Romanomermis culicivorax has been found to retain components of a developmental gene toolkit shared by primitive nematodes and most other ecdysozoans, which are however lost in Caenorhabditis elegans; on the other hand, the latter species has evolved many novel genes essential for its embryogenesis that are not found in $R$. culicivorax (Schiffer et al., 2013). Operationally, to concentrate efforts on a limited number of model species is a necessity, but we should not forget the peculiar tension experienced by evo-devo. On the one hand, the experimental approach characteristic of its developmental root asks for standardization (e.g., Frankino and Raff, 2004)thus the preference for inbred and selected strains, but also for highly uniform culture conditions. This is the context under which standard tables of developmental stages can be fixed and subsequently used for comparisons (e.g., Kimmel et al., 1995; Hopwood, 2007). On the other hand, the comparative and populational approach required by evolutionary biology is based on the study of individual and interpopulation variation, and on comparisons between closely related species. Moreover, and arguably most important, the role of phenotypic plasticity in developmental evolution goes frequently unnoticed, because this phenomenon has very meager opportunity to show up under the preferred experimental conditions (Robert, 2004; Love, 2008, 2010).

\section{QUESTIONS TO BE ADDRESSED}

Of the great challenges evo-devo is facing, a number are still distinctly identifiable as evolution-centered or developmentcentered. These are the questions briefly outlined in the next two sections. These questions do not exhaust the wealth of the intellectual challenges with which we will be confronted in a not too distant future. To be sure, precise predictions about the future of evo-devo are impossible (Hall, 2012), but the possibility, and in consequence the responsibility, is to an extent in our hands to steer the boat toward intellectually rewarding paths. We are already witnessing our discipline expanding its scope by exploring its boundaries toward other disciplines, ecology in particular (eco-evodevo, e.g., Hall, 2003; Gilbert and Epel, 2008; also evo-devo vs. niche construction, e.g., Laland et al., 2008), but also ethology (e.g., Bertossa, 2011) and the sciences of language (e.g., Hoang et al., 2011; Hall, 2013). Future advances in all these directions are welcome, but I expect that much more progress will come from the impact that evo-devo will eventually have on the foundations and the research agendas of its parent disciplines.

The impact of evo-devo on evolutionary biology is already visible, to the extent that evo-devo is explicitly held up as one of the disciplines whose results cannot be satisfactorily accommodated within the framework of the Modern Synthesis, but will essentially contribute to a new Extended Synthesis (Pigliucci and Müller, 2010). Stressing the expected leading role of evo-devo in such a conceptual expansion, Gilbert (2009) has suggested 
that evo-devo will eventually become synonymous with evolutionary biology.

Irrespective of the future course and success of the Extended Synthesis programme, this currently popular focus on the evolution side of evo-devo has produced a serious disregard for the consequences of evo-devo for the other parental discipline, i.e., developmental biology. Compared to evolutionary biology, developmental biology has much less elaborated theoretical foundations (Minelli and Pradeu, 2014) to the extent that its subject, development, is rarely defined, and usually delimited in purely operational terms, as the progression of changes from the egg to the adult. Up to now, this naive conception of development has been also pervasive in evo-devo, with seriously negative effects, e.g., the pretty absolute disregard for unicellulars and the excessive focus on early embryonic stages to the disadvantage of other segments of development. However, in the long run we are starting to appreciate that the evolution of development is not simply a series of changes in developmental schedule, which are responsible for changing the shape of a beak, or the function of an appendage. Evolution has produced and is continuously producing new ways to develop, think of transitions from direct to indirect development, and vice versa; of the evolution of multigenerational life cycles; of the enormously various degrees at which maternal influence is exerted on the offspring, either in nutritional or in morphogenetic sense. Evolution has also produced and is continuously producing new ways to translate genetic and environmental information into predictable sequences of change, steadily moving forth and back the boundary between plasticity and genetic determinism. Moreover-and this is a generally overlooked aspect of development, and of its evolution, the eventual outcome of a developmental sequence extends well beyond the dimension of morphology, to encompass also "temporal phenotypes" (Minelli and Fusco, 2012) and the associated behavioral repertoire. Think, for example, of the chronological precision with which in some North American cicadas (Magicicada spp.) maturity is reached after exactly 13 or 17 years of embryonic plus post-embryonic development. These phenomena cannot be accommodated within the traditional view of development as a sequence of morphological changes deterministically controlled by the genetic programme, starting with an egg and progressing through increasingly more complex stages, eventually culminating with the production of an adult. Development is much more than this, it is also timing of events along the sequence of change, while the instructing role of the genome, and the value of the egg and the adult as the natural boundaries of development, are much less absolute, and much less foundational, than traditionally accepted.

Eventually, a revised (more flexible and more comprehensive) concept of development will require a strong revisitation of evo-devo's research agenda. This will open the way to addressing, at last, a set of fundamental problems related to the ways evolution has been "inventing" development in its main features, from cell differentiation to the deployment of complex life cycles. These are, in my opinion, the very big challenges for our discipline. I will return to these in the final section.

\section{EVOLUTION-CENTERED CHALLENGES THE ARRIVAL OF THE FITTEST}

Olson (2012) advocates a return of development, long excluded from traditional evolutionary biology, to the study of adaptation. It is true that factors other than natural selection, such as developmental constraints, can plausibly account for the unequal filling of the morphospace. However, whenever developmental biology is able to demonstrate that morphologies that would occupy currently empty parts of the morphospace can nevertheless be readily produced, this will turn into a rejection of the constraint hypothesis and lend instead support to hypotheses of adaptation.

Evo-devo may even help explain some of the most "abominable" stories of adaptation, namely, the evolution of deceptively similar color patterns in the partners of Batesian and Müllerian mimicry systems. Of course, experimental tests of the actual survival advantages obtained from agreeing in color patterns are a necessary step to dispose of naïve unsubstantiated claims. However, these tests cannot help understanding how these exquisite stories of adaptation may have been initiated. It is therefore sensible to enquire if, or to which extent, the color pattern shared by model and mimic (in a Batesian scenario) or two co-mimics (in a Müllerian one) involves the same morphological units (e.g., the same sclerites of the exoskeleton of a stinging wasp and its hoverfly mimic) and/or the same genes, and to define their evolvability. Did the mimicry evolve more easily because the color pattern shared by model and mimic was constrained by the evolvability of the same body parts, and of the genes controlling their color pattern? A similar prediction was formulated by Nijhout (1991) with reference to the generalized wing pattern shared by even distantly related members of the Lepidoptera. This question is to be addressed in the light of the studies suggesting that the evolution of conspicuous adaptive traits is often controlled by a small number of genes with large phenotypic effects (e.g., Bradshaw et al., 1998; Cresko et al., 2004; Colosimo et al., 2005; Montgomery et al., 2011). In the butterflies of the genus Heliconius, Joron et al. (2006) have shown that homologous genes (or gene complexes) regulate convergence in Müllerian mimics. However, one and the same "developmental hotspot" (Richardson and Brakefield, 2003) can be responsible for both convergence and divergence of a trait (Joron et al., 2006).

These cases of mimicry are of special interest because they cluster along the problematic edge separating parallelism from convergence (e.g., Willmer, 2003; Powell, 2007; Minelli, 2009; Pearce, 2012), but a serious look to evolvability would be rewarding also in more "ordinary" instances of convergence (e.g., the raptorial maxillipedes in two groups of insects-the hemimetabolous mantids and the holometabolous mantipsids - and a group of crustaceans, i.e., the mantis shrimps) and of parallelism too. Very aptly, Brakefield (2006) commented from this perspective on the numerous examples of parallel evolution and adaptive radiation, starting from different founders, between the haplochromine cichlid fishes of the large lakes of the African Rift Valley (Kocher et al., 1993; Albertson and Kocher, 2006). Evolution by natural selection can well explain the adaptive feature of the individual species, but the wealth of identical solutions evolved in parallel in the 
different lakes cannot be explained except in the light of strong bias in the available variation (Brakefield, 2006).

\section{CONSTRAINTS ON DEVELOPMENTAL EVOLUTION}

A better knowledge of the genotype $\rightarrow$ phenotype map, and of the anisotropic patterns of evolvability, will eventually bring us closer to predicting at least some short segment of morphological evolution. Evo-devo's world is indeed one of biased embryos (Arthur, 2004). Generalizations, however, are dangerous. In most instances, "statements about [developmental or evolutionary] constraints are in fact statements about the relative frequency of particular transformations ...the same transformation may be constrained in one developmental or phylogenetic context, but evolutionarily plastic in another" (Richardson and Chipman, 2003). In other terms, recognizing a constraint pertains more to the classificatory than to the explanatory side of biology (cf. Wilkins and Ebach, 2013). At this level, a phylogenetic approach will be precious because of the expected negative correlation between the observed degree of homoplasy and the number of evolvable states (Donoghue and Ree, 2000). But this must not be the end of the story, as recognizing constraints in the context of evo-devo (Fusco, 2001) will eventually represent a vantage point from which to circumscribe and eventually attack the problem at a mechanistic, explanatory level.

\section{IS EVOLUTION REVERSIBLE?}

Interest in Dollo's (1893) law of the irreversibility of evolution has re-emerged since the advent of cladistics, which provides rigorous methods for reconstructing phylogeny, and of modern methods for dating evolutionary events, jointly based on the molecular clock and the fossil record. Several studies seem to seriously challenge Dollo's law, e.g., Wiens's (2011) study suggesting that mandibular teeth lost in the ancestor of modern frogs at least 230 million years ago have evolved anew in the frog genus Gastrotheca in the last ca. 5-17 million years.

In evo-devo, questions about the reversibility of evolution shift from the traditional level of morphology to questions about the possible evolutionary reversal of changes in developmental mechanisms. Some recent studies encourage further work in this direction. Sucena et al. (2014) have investigated the potential reversion from long to short germband in the braconid wasps, which ancestrally display long germband development (itself a derived condition within insects) but short germband development has secondarily evolved in the polyembryonic species Macrocentrus cingulum, suggesting that evolutionary change in germband size in insects is a reversible process. Similarly, the peculiar abdominal appendages evolved in the male sepsid flies have been shown by Bowsher et al. (2013) to have likely appeared only once, but within the family these appendages have been lost three times, and secondarily re-evolved in one lineage.

\section{SALTATIONAL EVOLUTION AND DISCONTINUOUS VARIATION}

Hypotheses of saltational evolution have been traditionally rejected for several reasons, ranging from strict respect for the Lyellian-Darwinian tradition, to the advocacy of a strong version of the parsimony principle, but often-more seriouslybecause the advocates of saltational evolution could only offer circumstantial evidence in favor of their views, without the support of experimental evidence or at least of a plausible hypothetical mechanism. Things are different in the light of current knowledge in developmental genetics, to the extent that many authors accept that "smaller changes and larger transitions are likely mixed together along the evolutionary history of life" (Orr, 1998).

Theißen (2009) has explicitly defended saltational evolution as a concept necessary to describe a number of key innovations and changes in body plan that have not possibly evolved in the more common, but far from universal gradualistic mode. For example, a single-gene mutation was probably responsible for the evolution of the bilaterally symmetrical orchid flower from an ancestor with radially symmetrical ones (Mondragón-Palomino and Theißen, 2008). Similarly, a small genetic change may explain the sudden duplication of the number of leg pairs uniquely observed in a lineage of scolopenders
(Minelli et al., 2009). Quite popular, in the evo-devo literature, is the case of the turtles, unique among the tetrapods in having the pectoral girdle encased within the ribs rather than external to it. Gilbert et al. (2001) and Rieppel (2001) did not hesitate to describe this change as saltational.

\section{NOVELTY BY HORIZONTAL GENE TRANSFER}

As recently claimed by Boto (2014), there is increasing evidence for the role of horizontal gene transfer in the acquisition of novel traits. This has been shown in animals as different as sponges, cnidarians, rotifers, nematodes, molluscs and arthropods. To date, however, we have no clear idea of the extent to which the phenomenon may have actually contributed to the evolution of form. Welltargeted studies in this area are likely to be rewarding.

\section{EXAPTATION OF DEVELOPMENTAL PROCESSES}

Is seems reasonable to expect that stories of exaptation will ordinarily bridge the gap between the arrival of the fittest (the step of evolutionary history targeted by evo-devo) and the survival of the fittest (the step targeted instead by traditional approaches to evolution). This will happen at all levels, from single-gene expression to the production of complex organs. Multiple, independent exaptation events of the same trait under similar selective pressure may explain a number of instances of parallelism and convergence, as in the controversial case of the evolution of metazoan eyes, where pax6 or one of its homologs has been likely exapted more than once from pigment specifier to eye specifier (Kozmik, 2005).

Exaptation is also likely involved in the evolution of a derived life cycle, or a derived life style, as in the transition from free-living to parasitic life styles in terrestrial nematodes. In several nematodes, indeed, environmental signals correlated with adverse external conditions can induce the worm to arrest its development as a dauer larva. A dauer larva can eventually turn into a pre-adaptation for the evolution of parasitism, as suggested by the cooption and subsequent modification, in the parasitic Parastrongyloides trichosuri, of the sensory transduction machinery responding to the external cues 
ordinarily inducing the switch to dauer larva in free-living nematodes (Stasiuk et al., 2012).

\section{REVISITING HOMOLOGIES AND PHYLOGENY}

In principle at least, evo-devo should be the ideal ground on which to look for integration between two different ways to approach homology (Minelli and Fusco, 2013a). On the one hand there are the historical concepts, including the notions of homology formulated by cladistics, based on the identification of shared modifications, or synapomorphies. On the other hand there are the proximalcause concepts of homology, based on the recognition of a shared genetic or epigenetic basis. The most popular among these notions is Wagner's (1989) biological notion of homology, based on the identification of shared underlying developmental processes, or strongly integrated developmental modules. Analysis in terms of modules (e.g., Raff and Sly, 2000; Schlosser and Wagner, 2004; Callebaut and Rasskin-Gutman, 2005) of the phenotype, and of the developmental processes responsible for it, make the latter notion more attractive to the evo-devoist. Most important, this approach in the general case allows the recognition of homologs that do not correspond necessarily to body parts with a distinct topographic and/or functional identity, like wings, fingers, and eyes, i.e., the units the morphologist and the systematist typically choose to base descriptions and comparisons (e.g., Minelli and Fusco, 1995). Eventually, an evo-devo approach to homology is likely to support a factorial (or combinatorial) concept of homology (Minelli, 1998) rather than a hierarchical one. The latter, traditional view is tightly linked to the naive idea that characters can change from a state to another but eventually "remain themselves," faithful to Owen's (1843) classic (and pre-evolutionary) definition of homolog as "the same organ in different animals under every variety of form and function"-an all too problematic definition in the light of the way organisms likely evolve.

A critically important implication of adopting a combinatorial concept of homology must be made explicit, that is, that body organs like the brain, the lungs and the heart, fade away from the list of homologs, each of them being a crossroad of developmental modules, i.e., of biological homologs. But this is not simply relevant for the taxonomist in search of independent characters for his/her data matrix. Irrespective of their distinct morphofunctional identity, organs cannot be further accepted as integrated units of development and specific chapters on organogenesis, e.g., cardiogenesis and cerebrogenesis (as such) should arguably disappear from the developmental biology literature (Minelli, 2009).

Revisiting homology based on comparative expression patterns of developmental genes presents us often with intriguing results, e.g., in the case of germ layer homology. In Caenorhabditis elegans, due to the very small total number of cells in the embryo, there is no morphological evidence for germ layers, but endoderm-specific genes have been found nevertheless (Maduro and Rothman, 2002). More attention has been given to date to the mesoderm, where genes such as snail and twist are characteristically expressed. A snail homolog has been found in a coral (Hayward et al., 2004) and a sea anemone (Martindale et al., 2004), where it seems to contribute to specifying the endoderm in respect to the ectoderm (Martindale et al., 2004; Ball et al., 2004), and a twist homolog has been found in the hydrozoan Podocoryne carnea (Spring et al., 2000). These findings may contribute to solve the dispute about the presence of mesoderm in the Cnidaria (e.g., Boero et al., 1998; Seipel and Schmid, 2005, 2006; Burton, 2008).

In addition to contributing to a revisitation of homologies, evo-devo can contribute original data to the reconstruction of phylogeny, especially through a comparative analysis of sequence heterochrony (e.g., Velhagen, 1997; Smith, 2001; Bininda-Emonds et al., 2002; Jeffery et al., 2005; Minelli et al., 2007). This approach deserves strong additional effort, especially in plants, where its potential is still virtually unexploited.

\section{PARAMORPHISM}

It has become fashionable to interpret major events in the evolution of the genetic control of development in terms of co-option of individual genes or even of whole gene regulatory networks (e.g.,
Bolker and Raff, 1996; True and Carroll, 2002; Hinman and Davidson, 2007; Shubin et al., 2009; Chipman, 2010).

However, we should advocate gene cooption only when an existing gene gets a new role in a developmental process in which it was not previously involved (or in a body part where it was previously not expressed) only provided that the developmental process (or the body part) with which it now becomes involved was already in existence (Minelli, 2009). The concept of co-option does not apply when a novel pattern of expression of a gene, or of a whole gene regulative network, coincides with the origination of a new body part, a context for which I proposed the term paramorphism (Minelli, 2000, 2003a), more specifically to describe the relationship between an already existing body axis and a new (lateral) axis depending on the iteration of existing developmental dynamics already responsible for the main body axis. Co-option indeed leaves unexplained how the new axis eventually emerged, prior to and independent of the co-option event. The main problem with this explanation is how the animal may have evolved new tools for producing the secondary body axes, and how these were prevented from negatively interfering with the growth and patterning of the main axis. This difficulty does not exist under the hypothesis of paramorphism, in which the evolution of a new axis and its patterning under the control of genes already expressed along the main body axis are essentially one and the same event.

Paramorphism is also other than serial homology. Body parts in serial homology are repeated along the same axis (either the main body axis, as in the case of our vertebrae, or a lateral axis, as for the articles of an insect's antenna), whereas those related by paramorphism belong to axes of different order. These can be either real axes, as those of appendages in respect to the main body axis, or virtual axes, as are those along which are expressed the genes responsible for patterning the "eyes" on the wings of several butterflies (Carroll et al., 1994). In the original formulation (Minelli, 2000), paramorphs are the axes themselves.

It may deserve serious thought to consider if this scenario can be extended 
beyond the domain of body axes, to apply also to other examples of ectopic extension of the expression of a gene, or a gene cassette, such as probably implied in the development of accessory hearts (e.g., wing hearts) in insects (Pass, 1998; Tögel et al., 2008).

\section{EVOLUTIONARY TRANSITIONS}

In the last two decades, i.e., since the publication of Maynard Smith and Szathmáry's (1995) book, questions in evolutionary biology have been increasingly framed in terms of transitions, and increasingly less frequently in term of origins. This is a welcome trend that should be encouraged in evo-devo too. As a consequence, a set of key questions in evo-devo can be listed in terms of searching for the developmental underpinnings of evolutionary transitions, e.g., transitions from uni- to multicellularity, from direct to indirect development, from unsegmented to segmented body organization. All these transitions obviously open the scope for research about parallelism, convergence, and reversal of trends.

\section{DEBUNKING TYPOLOGY, AND FOCUSSING ON MORPHOLOGICAL STASIS}

As mentioned above, most of the so-called developmental or evolutionary constraints are nothing more than highly frequent, or highly conserved states, or processes. Their pervasive distribution causes us to accept a number of body plans as "normal" and to look at their exceptions as the results of singular evolutionary events at which some constraint was broken. This attitude is best represented by the term morphological misfit introduced (in botany) by Bell (1991, 2008) to denote those plant forms "that cannot as yet sensibly be accommodated in traditional descriptions" (Bell, 2008, p. 247).

Examples of the numerical marginality of these unusual organisms are provided by the duckweed (34 species, i.e., 0.01\% of the flowering plants), tiny flowering water plants whose most derived representatives (Wolffia) are reduced to minuscule blobs of green cells, and the monotremes, i.e., the platypus and the echidnas (four species, less than $0.1 \%$ of living mammal species).

From an evolutionary point of view, prolonged morphological stasis is perhaps as interesting as is change, and the corresponding developmental underpinnings should therefore be targeted by evo-devo, which is currently too strongly focussed on the developmental basis of the evolution of innovations.

\section{DEVELOPMENT-CENTERED CHALLENGES \\ DEBUNKING ADULTOCENTRISM}

Developmental biology is seriously deformed by adultocentrism (Minelli, 2003b), that is, by the implicitly teleological view of development as targeted to produce an adult. One important manifestation of adultocentrism is the common disregard for the distinction between adult and mature (Minelli and Fusco, 2013b), a distinction that becomes most obvious in the case of heterochrony, of progenesis especially (e.g., de Beer, 1930, 1940; Gould, 1977).

Another serious deformation comes from the widespread tendency to regard the whole segment of individual life subsequent to the reproductively mature phase as a disturbing appendage to what is worth being called development. This tendency is related to the evolutionary perspective, according to which the traits of a senescent organism are irrelevant because selection has no effect on them. However, even in strictly evolutionary terms the post-reproductive segment of life cannot be ignored, because some of its traits can be eventually the source of heritable exaptations. In mechanistic terms, maturity can be separated from pre-maturity only in an arbitrary way; moreover, once maturity is first reached, the subsequent reproductive activity is very often discontinuous, intervals between subsequent reproductive periods being sometimes accompanied by extensive morphological and functional regression of the gonads and of the other reproductive structures.

\section{FUNDAMENTAL PRINCIPLES OF DEVELOPMENT?}

A number of researchers are looking to evo-devo as a biological discipline whose comparative nature offers hope to identify fundamental aspects of development (Vervoort, 2014). Recently, the discovery of an oscillatory process associated with the sequential production of root primordia in plants has invited comparisons with the segmentation clocks known from vertebrates and arthropods. This has lead to the suggestion that a segmentation clock is perhaps a fundamental principle governing patterning in growing tissues (Richmond and Oates, 2012). But this prima facie attractive suggestion does not correspond to the discovery of an evolutionarily ancestral mechanism. It is difficult to imagine the presence of something equivalent to a segmentation clock, in the common ancestors of plants and metazoans, except for a cellular oscillator that had nothing to do with segmentation or the like, before being exapted in such a role, something that would eventually happen in a very distant future. It seems therefore legitimate to ask: what should we regard as fundamental principles of development, if any? The question is clearly open for debate, in the light of a carefully formulated definition of development but also, perhaps, through the identification of recognizable "modules" to search for possible "fundamental principles."

A serious problem is the obvious lack of agreement on what "fundamental principles" should eventually be. By explicitly pointing to the heuristic value of homoplasious (parallel or convergent) features, Vervoort (2014) argued outside of a historical framework, whereas others would rather look for aspects of development we may regard as synapomorphies-if any of these are eventually to be found-shared by all the living beings that undergo development. Let's take for granted the cautionary note that in one or more lineages some of these features may have secondarily disappeared, or evolved to the extent of becoming unrecognizable. This second perspective is perhaps an obligate choice, if we want to study development in an evolutionary context. But this, in turn, may force us to go beyond development as featured by multicellulars, to seriously address life processes in unicellular and, perhaps, also in subcellular (or noncellular) contexts. As remarked by Griesemer and Szathmáry (2009), despite the empirical fact that life, as we know it, is inherently cellular, it is nevertheless problematic to take cellularity as a necessary condition when we try to characterize or define development. 


\section{CONSERVED PHASES vs. HOT-POINTS OF CHANGE ALONG THE DEVELOPMENTAL SCHEDULE}

One of the most obvious consequences of the focus on animal systems that dominates evo-devo is the frequent description of embryonic development in terms of the so-called hourglass model, to signify that the earliest stages are more extensively and more easily divergent than later embryonic stages (Duboule, 1994; Raff, 1996; Hall, 1997). The developmental trajectories of the members of the same major group converge toward the so-called phylotypic stage, at which their mutual resemblance is highest, but subsequently diverge in a more or less strict accordance to von Baer's (1828) "law of development." Early divergence is sometimes noticeable even at intraspecific level, as shown by Tills et al. (2011) for the pond snail, Radix balthica. As expected, gene expression is maximally conserved around the phylotypic period (e.g., Kalinka et al., 2010; Levin et al., 2012).

Interestingly, the distribution of more conserved and more variable segments of ontogenetic development is apparently correlated with genome organization. This is suggested by a comparison between vertebrates and amphioxus, on the one side, and tunicates, on the other (Holland, 2014). The genome of tunicates has undergone substantial divergent evolution, along which key developmental genes have been discarded, while their coding sequences have been integrated into "operons," which are transcribed as a single mRNA. In parallel, tunicates have adopted a very early determination of cell fate. As a consequence, their phylotypic stage occurs at a very early phase of development. According to Linda Holland, this can help explain the exceptional diversity of tunicate body plans.

Besides looking more in detail into this paradigmatic case, it will be worth investigating systematically the distribution of hot points of change along the ontogenetic schedules of other animals and to enquire whether/how this research program can be exported to groups other than metazoans.

\section{TWO VERY GREAT CHALLENGES POLYPHENISM TO POLYMORPHISM-THE INTERNALIZATION OF RELEASING INPUTS}

We can hardly imagine an organism developing in full independence from physi- cal and chemical inputs from the environment. This interdependence becomes more interesting, however, when genetically identical organisms develop along divergent but predicable paths if exposed to specifically different environmental cues-in other words, if they exhibit phenotypic plasticity (Schlichting and Pigliucci, 1998; Greene, 1999; Pigliucci, 2001; West-Eberhard, 2003; DeWitt and Scheiner, 2004; West-Eberhard, 2005a; Fusco and Minelli, 2010), eventually translating into a well-defined and predictable polyphenism.

Recent studies on the pea aphid Acyrthosiphon pisum (Brisson, 2010) have shown how easily alternative phenotypes produced under environmental control can evolve into genetically determined phenotypes, or vice versa. Pea aphids of either sex can be either winged or wingless, but in the females this is an environmentally controlled polyphenism whereas in the male the difference is controlled by a single-gene polymorphism (Braendle et al., 2005a). However, the protein encoded by the gene (aphicarus) responsible for wing development in the male aphid is also involved in the female's developmental response to the environmental stimulus (Braendle et al., 2005b).

This brings us straight into the exciting research field of genetic accommodation, the process by which a phenotype originally produced in response to an environmental condition, later becomes genetically encoded (e.g., West-Eberhard, 2003, 2005b; Moczek, 2007, 2008; Moczek et al., 2011; Schlichting and Wund, 2014). Under this broad umbrella, Waddington's (1953) genetic assimilation is the special case in which selection has favored the loss of plasticity (Robinson and Dukas, 1999; Pigliucci and Murren, 2003). The case in which plasticity enhances the survival of an individual in a new environment and selection subsequently favors heritable variation to accumulate in the direction of the plastic response, is currently known as the Baldwin effect (Baldwin, 1896; see also e.g., Crispo, 2007; Badyaev, 2009).

In addition, because of its expression being conditional to the exposure to environments not experienced for more or less long time, part of the genetic variation involved in phenotypic plasticity can be subject to relaxed selection, and eventually accumulate in the population in the form of cryptic variation (Gibson and Dworkin, 2004; Le Rouzic and Carlborg, 2008; Lahti et al., 2009; Snell-Rood et al., 2010; Van Dyken and Wade, 2010). Environmental changes can eventually unmask this cryptic variation and expose it to selection, with the possible release of novel phenotypes (Barrett and Schluter, 2008; Pfennig et al., 2010).

In the conventional sense, the term polyphenism applies to the production of alternative phenotypes at the level of the individual organism, in the absence of genetic differences. However, from a mechanistic point of view, polyphenism is closely comparable to cell differentiation within a developing multicellular, as well as to the sequential production of morphologically different stages along an organism's ontogeny. In a sense, sets of alternatively differentiated cells within an individuals can be equated to a set of divergent phenotypes of a polymorphic species, deprived of physical individuality (Zakhvatkin, 1949). In the case of developmental stages along an organism's ontogeny, we confront again the production of divergent phenotypes in the absence (most generally) of genotypic differences (Minelli and Fusco, 2010). In a sense, cell differentiation and phenotypic changes along the ontogeny can be regarded as spatially (cell differentiation) or temporally (sequence of developmental stages) integrated, internalized expressions of phenotypic plasticity. This view does potentially open an extraordinary rich research program in evo-devo, within a unitary framework that will hopefully bring us closer to the ways by which evolution has been "inventing" development.

\section{EPIGENETICS}

From an evo-devo perspective, epigenetic mechanisms (in the current sense of temporarily inheritable, functional markings of chromatin) can be regarded as tools involved in the production of a phenotype starting from a genotype and, as such, currently integrated into the genotype $\rightarrow$ phenotype map. How this integration evolved in the different groups is a virtually unexplored field that fully deserves attention from evo-devo.

Within this framework there will be also scope for investigating the evolution 
of less conventional biological products as are plant galls, with their often amazing morphological specificity that cannot be directly correlated with the genome of either the host plant or the inducing agent. Interestingly, the plant cells forming the gall are frequently polyploid (e.g., Kostoff and Kendall, 1929), with degree of polyploidy increasing toward the core of the gall. Why should this macroscopic change of chromatin matter not be considered as an induced epigenetic effect? It would be rewarding to compare this system with those where animal or plant form seems to be directly or indirectly controlled by one genome only, but I would bet that epigenetic influences of other, mostly microbial genomes will turn out to be frequent and pervasive.

We do not need to embrace Developmental System Theory (e.g., Oyama, 2000; Oyama et al., 2001; Pradeu, 2010) to accept that development is much more than morphological change produced by sequential and tightly controlled gene expression. Environmental influences, and their probably widespread transgenerational effects, are part and parcel of the ways animal and plants develop. However, these influences, far from being "noise" we should better leave out of the picture, are part of the developmental system-its scaffolds perhaps (Griesemer, 2014a,b). But the resulting "hybrid" developmental system (the conventional organism plus its scaffold) will obviously evolve, as the subject matter of an epigenetic evo-devo of which until now we have little more than the name.

\section{ACKNOWLEDGMENTS}

Many thanks to Giuseppe Fusco, Armin P. Moczek and Mark E. Olson for stimulating and constructive comments on a previous version of this article.

\section{REFERENCES}

Alberch, P. (1991). From genes to phenotype: dynamical systems and evolvability. Genetica $84,5-11$. doi: 10.1007/BF00123979

Albertson, R. C., and Kocher, T. D. (2006). Genetic and developmental basis of cichlid trophic diversity. Heredity (Edinb.) 97, 211-221. doi: 10.1038/sj.hdy.6800864

Altenberg, L. (1995). "Genome growth and the evolution of the genotype-phenotype map," in Evolution and Biocomputation. Computational Models of Evolution, eds W. Banzhaf and F. H. Eeckman (Berlin: Springer), 205-259.
Amundson, R. (2005). The Changing Role of the Embryo in Evolutionary Thought: Roots of EvoDevo. New York, NY: Cambridge University Press. doi: 10.1017/CBO9781139164856

Arthur, W. (2004). Biased Embryos and Evolution. Cambridge: Cambridge University Press. doi: 10.1017/CBO9780511606830

Badyaev, A. V. (2009). Evolutionary significance of phenotypic accommodation in novel environments: an empirical test of the Baldwin effect. Philos. Trans. R. Soc. Lond. B 364, 1125-1141. doi: 10.1098/rstb.2008.0285

Baldwin, J. M. (1896). A new factor in evolution. Am. Nat. 30, 441-451, 536-553.

Ball, E. E., Hayward, D. C., Saint, R., and Miller, D. J. (2004). A simple plan - cnidarians and the origins of developmental mechanisms. Nat. Rev. Genet. 5, 567-577. doi: 10.1038/nrg1402

Barrett, R. D. H., and Schluter, D. (2008). Adaptation from standing genetic variation. Trends Ecol. Evol. 23, 38-44. doi: 10.1016/j.tree.2007.09.008

Bell, A. (1991). Plant form: An Illustrated Guide to Flowering Plant Morphology. Oxford: Oxford University Press.

Bell, A. (2008). Plant form: An Illustrated Guide to Flowering Plant Morphology, New Edn. Portland, OR: Timber Press.

Bertossa, R. C. (2011). Morphology and behaviour: functional links in development and evolution. Philos. Trans. R. Soc. B 366, 2056-2068. doi: 10.1098/rstb.2011.0035

Beurton, P. J., Falk, R., and Rheinberger, H.-J. (2000). The Concept of the Gene in Development and Evolution: Historical and Epistemological Perspectives. New York, NY: Cambridge University Press. doi: 10.1017/CBO9780511527296

Bininda-Emonds, O. R. P., Jeffery, J. E., Coates, M. I., and Richardson, M. K. (2002). From Haeckel to event-pairing: the evolution of developmental sequences. Theory Biosci. 121, 297-320. doi: 10.1007/s12064-002-0016-5

Boero, F., Gravili, C., Pagliara, P., Piraino, S., Bouillon, J., and Schmid, V. (1998). The cnidarian premises of metazoan evolution: from triploblasty, to coelom formation, to metamery. Ital. J. Zool. 65, 5-9. doi: 10.1080/11250009809386722

Bolker, J. A., and Raff, R. A. (1996). Developmental genetics and traditional homology. Bioessays 18, 489-494. doi: 10.1002/bies.950180611

Boto, L. (2014). Horizontal gene transfer in the acquisition of novel traits by metazoans. Proc. Biol. Sci. 281, 20132450. doi: 10.1098/rspb.2013. 2450

Bowsher, J. H., Ang, Y., Ferderer, T., and Meier, R. (2013). Deciphering the evolutionary history and developmental mechanisms of a complex sexual ornament: the abdominal appendages of Sepsidae (Diptera). Evolution 67, 1069-1080. doi: 10.1111/evo.12006

Bradshaw, H. D., Otto, J., Frewen, B. E., McKay, J. K., and Schemske, D. W. (1998). Quantitative trait loci affecting differences in floral morphology between two species of monkeyflower (Mimulus). Genetics 149, 367-382.

Braendle, C., Caillaud, M. C., and Stern, D. L. (2005a). Genetic mapping of aphicarus - a sex-linked locus controlling a wing polymorphism in the pea aphid (Acyrthosiphon pisum). Heredity 94, 435-442. doi: 10.1038/sj.hdy.6800633
Braendle, C., Friebe, I., Caillaud, M. C., and Stern, D. L. (2005b). Genetic variation for an aphid wing polyphenism is genetically linked to a naturally occurring wing polymorphism. Proc. R. Soc. B Biol. Sci. 272, 657-664. doi: 10.1098/rspb.2004.2995

Brakefield, P. M. (2006). Evo-devo and constraints on selection. Trends Ecol. Evol. 21, 362-368. doi: 10.1016/j.tree.2006.05.001

Brisson, J. A. (2010). Aphid wing dimorphisms: linking environmental and genetic control of trait variation. Philos. Trans. R. Soc. B Biol. Sci. 365, 605-616. doi: 10.1098/rstb.2009.0255

Burton, P. M. (2008). Insights from diploblasts; the evolution of mesoderm and muscle. J. Exp. Zool. Mol. Dev. Evol. 310B, 5-14. doi: 10.1002/jez.b. 21150

Callebaut, W., and Rasskin-Gutman, D. (eds.). (2005). Modularity: Understanding the Development and Evolution of Natural Complex Systems. Cambridge, MA: MIT Press.

Carroll, S. B., Gates, J., Keys, D. N., Paddock, S. W., Panganiban, G. E. F., Selegue, J. E., et al. (1994). Pattern formation and eyespot determination in butterfly wings. Science 265, 109-114. doi 10.1126/science.7912449

Chipman, A. D. (2010). Parallel evolution of segmentation by cooption of ancestral gene regulatory networks. Bioessays 32, 60-70. doi: 10.1002/bies.200900130

Claridge, M. F., Dawah, H. A., and Wilson, M. R. (eds.). (1997). Species: The Units of Biodiversity. London: Chapman \& Hall.

Colosimo, P. F., Hosemann, K. E., Balabhadra, S., Villarreal, G., Dickson, M., Grimwood, J., et al. (2005). Widespread parallel evolution in sticklebacks by repeated fixation of ectodysplasin alleles. Science 307, 1928-1933. doi: 10.1126/science.1107239

Cresko, W. A., Amores, A., Wilson, C., Murphy, J., Currey, M., Phillips, P., et al. (2004). Parallel genetic basis for repeated evolution of armor loss in Alaskan threespine stickleback populations. Proc. Natl. Acad. Sci. U.S.A. 101, 6050-6055. doi: 10.1073/pnas.0308479101

Crispo, E. (2007). The Baldwin effect and genetic assimilation: revisiting two mechanisms of evolutionary change mediated by phenotypic plasticity. Evolution 61, 2469-2479. doi: 10.1111/j.15585646.2007.00203.x

de Beer, G. R. (1930). Embryology and Evolution. Oxford: Clarendon Press.

de Beer, G. R. (1940). Embryos and Ancestors. Oxford: Clarendon Press.

DeWitt, T. J., and Scheiner, S. M. (eds.). (2004). Phenotypic Plasticity: Functional and Conceptual Approaches. New York, NY: Oxford University Press.

Dollo, L. (1893). Les lois de l'évolution. Bull. Soc. Belge Géol. Paleontol. Hydrol. 7, 164-166.

Donoghue, M. J., and Ree, R. H. (2000). Homoplasy and developmental constraint: a model and example from plants. Am. Zool. 40, 759-769. doi: 10.1668/0003-1569(2000)040 [0759:HADCAM]2.0.CO;2

Duboule, D. (1994). Temporal colinearity and the phylotypic progression: a basis for the stability of a vertebrate Bauplan and the evolution of morphologies through heterochrony. Dev. Suppl. 1994, 135-142. 
Frankino, W. A., and Raff, R. A. (2004). "Evolutionary importance and pattern of phenotypic plasticity," in Phenotypic Plasticity: Functional and Conceptual Approaches, eds T. J. DeWitt and S. M. Scheiner (Oxford: Oxford University Press), 64-81.

Fusco, G. (2001). How many processes are responsible for phenotypic evolution? Evol. Dev. 3, 279-286. doi: 10.1046/j.1525-142x.2001.003004279.x

Fusco, G., and Minelli, A. (2010). Phenotypic plasticity in development and evolution. Philos. Trans. R. Soc. B Biol. Sci. 365, 547-556. doi: 10.1098/rstb.2009.0267

Gibson, G., and Dworkin, I. (2004). Uncovering cryptic genetic variation. Nat. Rev. Genet. 5, 1199-1212. doi: $10.1038 / \operatorname{nrg} 1426$

Gilbert, S. F. (2009). BIO. Evol. Dev. 11, 331-332. doi: 10.1111/j.1525-142X.2009.00339.x

Gilbert, S. F., and Epel, D. (2008). Ecological Developmental Biology: Integrating Epigenetics, Medicine, and Evolution. Sunderland: Sinauer Associates.

Gilbert, S. F., Loredo, G. A., Brukman, A., and Burke, A. C. (2001). Morphogenesis of the turtle shell: the development of a novel structure in tetrapod evolution. Evol. Dev. 3, 47-58. doi: 10.1046/j.1525142x.2001.003002047.x

Gould, S. J. (1977). Ontogeny and Phylogeny. Cambridge, MA: The Belknap Press of Harvard University Press.

Greene, E. (1999). "Phenotypic variation in larval development and evolution: polymorphism, polyphenism, and developmental reaction norms," in The Origin and Evolution of Larval Forms, eds M. Wake and B. K. Hall (New York, NY: Academic Press), 379-410.

Griesemer, J. (2014a). "Reproduction and scaffolded developmental processes: an integrated evolutionary perspective," in Towards a Theory of Development, eds A. Minelli and T. Pradeu (Oxford: Oxford University Press), 183-202.

Griesemer, J. (2014b). "Reproduction and the scaffolded development of hybrids," in Developing Scaffolds in Evolution, Culture, and Cognition, eds. L. Caporael, J. Griesemer, and W. Wimsatt (Cambridge, MA: MIT Press), 23-55.

Griesemer, J., and Szathmáry, E. (2009). "Gánti's chemoton model and life criteria," in Protocells: Bridging Nonliving and Living Matter, eds S. Rasmussen, M. A. Bedau, L.-H. Chen, D. Deamer, D. C. Krakauer, and P. F. Stadler (Cambridge, MA: MIT Press), 481-512.

Hall, B. K. (1997). Phylotypic stage or phantom, is there a highly conserved embryonic stage in vertebrates? Trends Ecol. Evol. 12, 461-463.

Hall, B. K. (2003). "Evolution as the control of development by ecology," in Environment, Evolution and Development: Towards a Synthesis, eds B. K. Hall, R. Pearson, and G. B. Müller (Cambridge. MA: MIT Press), ix-xxiii.

Hall, B. K. (2012). Evolutionary developmental biology (Evo-Devo): past, present, and future. Evol. Edu. Outreach 5, 184-193. doi: 10.1007/s12052012-0418-x

Hall, B. K. (2013). Homology, homoplasy, novelty, and behavior. Dev. Psychobiol. 55, 4-12. doi: 10.1002/dev.21039

Hayward, D. C., Miller, D. J., and Ball, E. E. (2004). Snail expression during embryonic development of the coral Acropora: blurring the diploblast/triploblast divide? Dev. Genes Evol. 214, 257-260. doi: 10.1007/s00427-004-0398-0

Hendrikse, J. L., Parsons, T. E., and Hallgrímsson, B. (2007). Evolvability as the proper focus of evolutionary developmental biology. Evol. Dev. 9, 393-401. doi: 10.1111/j.1525-142X.2007.00176.x

Hinman, V. F., and Davidson, E. H. (2007). Evolutionary plasticity of developmental gene regulatory network architecture. Proc. Natl. Acad. Sci. U.S.A. 104, 19404-19409. doi: 10.1073/pnas.0709994104

Hoang, T.-H., McKay, R. I., Essam, D., and Hoai, N. X. (2011). On synergistic interactions between evolution, development and layered learning. IEEE Trans. Evol. Comput. 15, 287-311. doi: 10.1109/TEVC.2011.2150752

Holland, L. Z. (2014). Genomics, evolution and development of amphioxus and tunicates: the Goldilocks principle. J. Exp. Zool. Mol. Dev. Evol. doi: 10.1002/jez.b.22569. [Epub ahead of print].

Hopwood, N. (2007). A history of normal plates, tables and stages in vertebrate embryology. Int. J. Dev. Biol. 51, 1-26. doi: 10.1387/ijdb.062189nh

Jeffery, J. E., Bininda-Emonds, O. R. P., Coates, M. I., and Richardson, M. K. (2005). A new technique for identifying sequence heterochrony. Syst. Biol. 54, 230-240. doi: 10.1080/10635150590923227

Jenner, R. A. (2006). Unburdening evo-devo: ancestral attractions, model organisms, and basal baloney. Dev. Genes Evol. 216, 385-394. doi: 10.1007/s00427-006-0084-5

Joron, M., Jiggins, C. D., Papanicolaou, A., and McMillan, W. O. (2006). Heliconius wing patterns: an evo-devo model for understanding phenotypic diversity. Heredity 97, 157-167. doi: 10.1038/sj.hdy.6800873

Kalinka, A. T., Varga, K. M., Gerrard, D. T., Preibisch, S., Corcoran, D. L., Jarrells, J., et al. (2010). Gene expression divergence recapitulates the developmental hourglass model. Nature 468, 811-814. doi: 10.1038/nature09634

Kimmel, C. B., Ballard, W. W., Kimmel, S. R., Ullmann, B., and Schilling, T. F. (1995). Stages of embryonic development of the zebrafish. Dev. Dyn. 203, 253-310. doi: 10.1002/aja.1002030302

Kocher, T. D., Conroy, J. A., McKaye, K. R., and Stauffer, J. R. (1993). Similar morphologies of cichlid fish in lakes Tanganyika and Malawi are due to convergence. Mol. Phylogenet. Evol. 2, 158-165. doi: 10.1006/mpev.1993.1016

Kostoff, D., and Kendall, J. (1929). Studies on the structure and development of certain cynipid galls. Biol. Bull. 56, 402-458.

Kozmik, Z. (2005). Pax genes in eye development and evolution. Curr. Opin. Genet. Dev. 15, 430-438. doi: 10.1016/j.gde.2005.05.001

Lahti, D. C., Johnson, N. A., Ajie, B. C., Otto, S. P., Hendry, A. P., Blumstein, D. T., et al. (2009). Relaxed selection in the wild. Trends Ecol. Evol. 24, 487-496. doi: 10.1016/j.tree.2009.03.010

Laland, K. N., Odling-Smee, J., and Gilbert, S. F. (2008). EvoDevo and niche construction: building bridges. J. Exp. Zool. Mol. Dev. Evol. 310, 549-566. doi: 10.1002/jez.b.21232

Le Rouzic, A., and Carlborg, O. (2008). Evolutionary potential of hidden genetic variation. Trends Ecol. Evol. 23, 33-37. doi: 10.1016/j.tree.2007.09.014

Levin, M., Hashimshony, T., Wagner, F., and Yanai, I. (2012). Developmental milestones punctuate gene expression in the Caenorhabditis embryo. Dev. Cell 22, 1101-1108. doi: 10.1016/j.devcel.2012.04.004

Love, A. C. (2008). Explaining evolutionary innovation and novelty: criteria of explanatory adequacy and epistemological prerequisites. Philos. Sci. 75, 874-886. doi: 10.1086/594531

Love, A. C. (2010). Idealization in evolutionary developmental investigation: A tension between phenotypic plasticity and normal stages. Philos. Trans. R. Soc. B Biol. Sci. 365, 679-690. doi: 10.1098/rstb.2009.0262

Maduro, M. F., and Rothman, J. H. (2002). Making worm guts: the gene regulatory network of the Caenorhabditis elegans endoderm. Dev. Biol. 246, 68-85. doi: 10.1006/dbio.2002.0655

Martindale, M. Q., Pang, K., and Finnerty, J. R. (2004). Investigating the origins of triploblasty: 'mesodermal' gene expression in a diploblastic animal, the sea anemone Nematostella vectensis (Phylum, Cnidaria; Class, Anthozoa). Development 131, 2463-2474. doi: 10.1242/dev.01119

Maynard Smith, J., and Szathmáry, E. (1995). The Major Transitions in Evolution. San Francisco, CA: W. H. Freeman.

Minelli, A. (1998). Molecules, developmental modules and phenotypes: a combinatorial approach to homology. Mol. Phylogenet. Evol. 9, 340-347. doi: 10.1006/mpev.1997.0490

Minelli, A. (2000). Limbs and tail as evolutionarily diverging duplicates of the main body axis. Evol. Dev. 2, 157-165. doi: 10.1046/j.1525142x.2000.00054.x

Minelli, A. (2003a). The origin and evolution of appendages. Int. J. Dev. Biol. 47, 573-581.

Minelli, A. (2003b). The Development of Animal Form. Cambridge: Cambridge University Press.

Minelli, A. (2009). Perspectives on Animal Phylogeny and Evolution. Oxford: Oxford University Press.

Minelli, A. (2011). Animal development, an openended segment of life. Biol. Theory 6, 4-15. doi: 10.1007/s13752-011-0002-6

Minelli, A. (2014). "Developmental disparity," in Towards a Theory of Development, eds A. Minelli and T. Pradeu (Oxford: Oxford University Press), 227-245.

Minelli, A., and Baedke, J. (2014). Model organisms in evo-devo: promises and pitfalls of the comparative approach. Hist. Philos. Life Sci. 36, 42-59. doi: 10.1007/s40656-014-0004-3

Minelli, A., Chagas-Júnior, A., and Edgecombe, G. D. (2009). Saltational evolution of trunk segment number in centipedes. Evol. Dev. 11, 318-322. doi: 10.1111/j.1525-142X.2009.00334.x

Minelli, A., and Fusco, G. (1995). "Body segmentation and segment differentiation: the scope for heterochronic change," in Evolutionary Change and Heterochrony, ed K. J. McNamara (London: Wiley), 49-63.

Minelli, A., and Fusco, G. (2010). Developmental plasticity and the evolution of animal complex life cycles. Philos. Trans. R. Soc. B Biol. Sci. 365, 631-640. doi: 10.1098/rstb.2009.0268

Minelli, A., and Fusco, G. (2012). On the evolutionary developmental biology of speciation. Evol. Biol. 39, 242-254. doi: 10.1007/s11692-012-9175-6

Minelli, A., and Fusco, G. (2013a). "Homology," in The Philosophy of Biology: A Companion for Educators, ed K. Kampourakis (Dordrecht: Springer), 289-322. 
Minelli, A., and Fusco, G. (2013b). "Arthropod post-embryonic development," in Arthropod Biology and Evolution. Molecules, Development, Morphology, eds A. Minelli, G. Boxshall, and G. Fusco (Heidelberg: Springer), 91-122.

Minelli, A., Negrisolo, E., and Fusco, G. (2007). "Reconstructing animal phylogeny in the light of evolutionary developmental biology," in Reconstructing the Tree of Life: Taxonomy and Systematics of Species Rich Taxa, eds T. R. Hodkinson, J. A. N. Parnell, and S. Waldren (Boca Raton, FL: Taylor \& Francis/CRC Press), 177-190.

Minelli, A., and Pradeu, T. (eds.). (2014). Towards a Theory of Development. Oxford: Oxford University Press. doi: 10.1093/acprof:oso/9780 199671427.001.0001

Moczek, A. P. (2007). Developmental capacitance, genetic accommodation, and adaptive evolution. Evol. Dev. 9, 299-305. doi: 10.1111/j.1525142X.2007.00162.x

Moczek, A. P. (2008). On the origins of novelty in development and evolution. Bioessays 30, 432-447. doi: 10.1002/bies.20754

Moczek, A. P., Sultan, S., Foster, S., Ledon-Rettig, C., Dworkin, I., Nijhout, H. F., et al. (2011). The role of developmental plasticity in evolutionary innovation. Proc. R. Soc. Lond. Ser. B 278, 2705-2713. doi: 10.1098/rspb.2011.0971

Mondragón-Palomino, M., and Theißen, G. (2008). MADS about the evolution of orchid flowers. Trends Plant Sci. 13, 51-59. doi: 10.1016/j.tplants.2007.11.007

Montgomery, S. H., Capellini, I., Venditti, C., Barton, R. A., and Mundy, N. I. (2011). Adaptive evolution of four microcephaly genes and the evolution of brain size in anthropoid primates. Mol. Biol. Evol. 28, 625-638. doi: 10.1093/molbev/msq237

Müller, G. B., and Newman, S. A. (2005). The innovation triad: an EvoDevo agenda. J. Exp. Zool. Mol. Dev. Evol. 304, 487-503. doi: 10.1002/jez.b.21081

Müller-Wille, S., and Rheinberger, H.-J. (2009). Das Gen im Zeitalter der Postgenomik-Eine Wissenschaftshistorische Bestandsaufnahme. Frankfurt: Suhrkamp.

Newman, S. A. (1992). "Generic physical mechanisms of morphogenesis and pattern formation as determinants in the evolution of multicellular organization," in Principles of Organization in Organisms, eds J. B. Mittenthal and A. B. Baskin (Reading, MA: Addison-Wesley), 241-267.

Newman, S. A. (1994). Generic physical mechanisms of tissue morphogenesis: a common basis for development and evolution. J. Evol. Biol. 7, 467-488. doi: 10.1046/j.14209101.1994.7040467.x

Nietzsche, F. (1887). Zur Genealogie der Moral. Cited in this article after the translation by Ian Johnston. Available online at: http://records.viu. $\mathrm{ca} \sim$ johnstoi/Nietzsche/genealogytofc.htm [Accessed October 29, 2014].

Nijhout, H. F. (1991). The Development and Evolution of Butterfly Wing Patterns. Washington, DC: Smithsonian Institution Press.

Olson, M. E. (2012). The developmental renaissance in adaptationism. Trends Ecol. Evol. 27, 278-287. doi: 10.1016/j.tree.2011.12.005

Orr, H. A. (1998). The population genetics of adaptation: the distribution of factors fixed during adaptive evolution. Evolution 52, 935-949. doi: $10.2307 / 2411226$

Owen, R. (1843). Lectures on the Comparative Anatomy and Physiology of the Invertebrate Animals, Delivered at the Royal College of Surgeons. London: Longman, Brown, Green and Longmans.

Oyama, S. (2000). The Ontogeny of Information: Developmental Systems and Evolution, 2nd Edn. Durham: Duke University Press. doi: 10.1215/9780822380665

Oyama, S., Griffiths, P., and Gray, R. (eds.). (2001). Cycles of Contingency: Developmental Systems and Evolution. Cambridge, MA: MIT Press.

Pass, G. (1998). "Accessory pulsatile organs," in Microscopic Anatomy of Invertebrates, 11B. Insecta, eds F. Harrison and M. Locke (New York, NY: Wiley), 621-640.

Pearce, T. (2012). Convergence and parallelism in evolution: a neo-gouldian account. Br. J. Philos. Sci. 63, 429-448. doi: 10.1093/bjps/axr046

Pfennig, D. W., Wund, M. A., Snell-Rood, E. C., Cruickshank, T., Schlichting, T. C., and Moczek, A. P. (2010). Phenotypic plasticity's impacts on diversification and speciation. Trends Ecol. Evol. 25, 459-467. doi: 10.1016/j.tree.2010.05.006

Pigliucci, M. (2001). Phenotypic Plasticity: Beyond Nature and Nurture. Baltimore, MD: Johns Hopkins University Press.

Pigliucci, M. (2010). Genotype $\rightarrow$ phenotype mapping and the end of the 'genes as blueprint' metaphor. Philos. Trans. R. Soc. B Biol. Sci. 365, 557-566. doi: 10.1098/rstb.2009.0241

Pigliucci, M., and Müller, G. (eds.). (2010). Evolution: The Extended Synthesis. Cambridge, MA: MIT Press.

Pigliucci, M., and Murren, C. (2003). Genetic assimilation and a possible evolutionary paradox: can macroevolution sometimes be so fast as to pass us by? Evolution 57, 1455-1464. doi: 10.1111/j.00143820.2003.tb00354.x

Powell, R. (2007). Is convergence more than an analogy? Homoplasy and its implications for macroevolutionary predictability. Biol. Philos. 22, 565-578. doi: 10.1007/s10539-006-9057-3

Pradeu, T. (2010). The organism in developmental systems theory. Biol. Theory 5, 216-222. doi: 10.1162/BIOT_a_00042

Raff, R. A. (1996). The Shape of Life: Genes, Development and the Evolution of Animal Form. Chicago, IL: University of Chicago Press.

Raff, R. A. (2000). Evo-devo: the evolution of a new discipline. Nat. Rev. Genet. 1, 74-79. doi: 10.1038/35049594

Raff, R. A., and Sly, B. J. (2000). Modularity and dissociation in the evolution of gene expression territories in development. Evol. Dev. 2, 102-113. doi: 10.1046/j.1525-142x.2000.00035.x

Richardson, M. K., and Brakefield, P. M. (2003). Hotspots for evolution. Nature 424, 894-895. doi: $10.1038 / 424894 a$

Richardson, M. K., and Chipman, A. D. (2003). Developmental constraints in a comparative framework: a test case using variations in phalanx number during amniote evolution. J. Exp. Zool. Mol. Dev. Evol. 296, 8-22. doi: 10.1002/jez.b.13

Richmond, D. L., and Oates, A. C. (2012). The segmentation clock: inherited trait or universal design principle? Curr. Opin. Genet. Dev. 22, 600-606. doi: 10.1016/j.gde.2012.10.003
Rieppel, O. (2001). Turtles as hopeful monsters. Bioessays 23, 987-991. doi: 10.1002/bies.1143

Robert, J. S. (2004). Embryology, Epigenesis, and Evolution: Taking Development Seriously. New York, NY: Cambridge University Press. doi: 10.1017/CBO9780511498541

Robinson, B. W., and Dukas, R. (1999). The influence of phenotypic modifications on evolution: the Baldwin effect and modern perspectives. Oikos 85 , 528-589. doi: 10.2307/3546709

Schiffer, P. H., Kroiher, M., Kraus, C., Koutsovoulos, G. D., Kumar, S., Camps, J. I. R., et al. (2013). The genome of Romanomermis culicivorax: revealing fundamental changes in the core developmental genetic toolkit in Nematoda. BMC Genomics 14:923. doi: 10.1186/1471-2164-14-923

Schlichting, C. D., and Pigliucci, M. (1998). Phenotypic Evolution: A Reaction Norm Perspective. Sunderland, MA: Sinauer.

Schlichting, C. D., and Wund, M. A. (2014). Phenotypic plasticity and epigenetic marking: an assessment of evidence for genetic accommodation. Evolution 68, 656-672. doi: 10.1111/evo. 12348

Schlosser, G., and Wagner, G. P. (2004). Modularity in Development and Evolution. Chicago, IL: University of Chicago Press.

Seipel, K., and Schmid, V. (2005). Evolution of striated muscle: jellyfish and the origin of triploblasty. Dev. Biol. 282, 14-26. doi: 10.1016/j.ydbio.2005. 03.032

Seipel, K., and Schmid, V. (2006). Mesodermal anatomies in cnidarian polyps and medusa. Int. J. Dev. Biol. 50, 589-599. doi: 10.1387/ijdb.062150ks

Shubin, N., Tabin, C., and Carroll, S. (2009). Deep homology and the origins of evolutionary novelty. Nature 457, 818-823. doi: 10.1038/nature07891

Smith, K. K. (2001). Heterochrony revisited: the evolution of developmental sequences. Biol. J. Linn. Soc. 73, 169-186. doi: $10.1111 / j .1095-$ 8312.2001.tb01355.x

Snell-Rood, E. C., Van Dyken, J. D., Cruickshank, T., Wade, M. J., and Moczek, A. P. (2010). Toward a population genetic framework of developmental evolution: costs, limits, and consequences of phenotypic plasticity. Bioessays 32, 71-81. doi: 10.1002/bies.200900132

Spring, J., Yanze, N., Middel, A. M., Stierwald, M., Gröger, H., and Schmid, V. (2000). The mesoderm specification factor Twist in the life cycle of jellyfish. Dev. Biol. 228, 363-375. doi: 10.1006/dbio.2000.9956

Stasiuk, S. J., Scott, M. J., and Grant, W. N. (2012). Developmental plasticity and the evolution of parasitism in an unusual nematode, Parastrongyloides trichosuri. Evodevo 3:1. doi: 10.1186/20419139-3-1

Sucena, É., Vanderberghe, K., Zhurov, V., and Grbić, M. (2014). Reversion of developmental mode in insects: evolution from long germband to short germband in the polyembrionic wasp Macrocentrus cingulum Brischke. Evol. Dev. 16, 233-246. doi: 10.1111/ede.12086

Theißen, G. (2009). Saltational evolution: hopeful monsters are here to stay. Theory Biosci. 128, 43-51. doi: 10.1007/s12064-009-0058-z

Tills, O., Rundle, S. D., Salinger, M., Haun, T., Pfenninger, M., and Spicer, J. I. (2011). A genetic basis for intraspecific differences in 
developmental timing? Evol. Dev. 13, 542-548. doi: 10.1111/j.1525-142X.2011.00510.x

Tögel, M., Pass, G., and Paululat, A. (2008). The Drosophila wing hearts originate from pericardial cells and are essential for wing maturation. Dev. Biol. 318, 29-37. doi: 10.1016/j.ydbio.2008.02.043

True, J. R., and Carroll, S. B. (2002). Gene cooption in physiological and morphological evolution. Annu. Rev. Cell Dev. Biol. 18, 53-80. doi: 10.1146/annurev.cellbio.18.020402.140619

Van Dyken, J., and Wade, M. J. (2010). The genetic signature of conditional expression. Genetics 84, 557-570. doi: 10.1534/genetics.109.110163

Velhagen, W. A. Jr. (1997). Analyzing developmental sequences using sequence units. Syst. Biol. 46, 204-210. doi: 10.1093/sysbio/46.1.204

Vervoort, M. (2014). "Comparison of animal and plant development: a right track to establish a theory of development?" in Towards a Theory of Development, eds A. Minelli and T. Pradeu (Oxford: Oxford University Press), 203-217.

von Baer, K. E. (1828). Über Entwicklungsgeschichte der Thiere: Beobachtung und Reflexion, 1. Königsberg: Bornträger.

Waddington, C. H. (1953). Genetic assimilation of an acquired character. Evolution 7, 118-126. doi: $10.2307 / 2405747$

Wagner, G. P. (1989). The biological homology concept. Annu. Rev. Ecol. Syst. 20, 51-69.
Wagner, G. P., and Zhang, J. (2011). The pleiotropic structure of the genotype-phenotype map: the evolvability of complex organisms. Nat. Rev. Genet. 12, 204-213. doi: 10.1038/ nrg2949

West-Eberhard, M. J. (2003). Developmental Plasticity and Evolution. New York, NY: Oxford University Press.

West-Eberhard, M. J. (2005a). Developmental plasticity and the origin of species differences. Proc. Natl. Acad. Sci. U.S.A. 102, 6543-6549. doi: 10.1073/pnas.0501844102

West-Eberhard, M. J. (2005b). Phenotypic accommodation: adaptive innovation due to developmental plasticity. J. Exp. Zool. Mol. Dev. Evol. 304B, 610-618. doi: 10.1002/jez.b.21071

Wiens, J. J. (2011). Re-evolution of lost mandibular teeth in frogs after more than 200 million years, and re-evaluating Dollo's law. Evolution 65, 1283-1296. doi: 10.1111/j.1558-5646.2011.01221.x

Wilkins, J. S., and Ebach, M. C. (2013). The Nature of Classification: Relationships and Kinds in the Natural Sciences. Basingstoke: Palgrave Macmillan. doi: $10.1057 / 9781137318121$

Willmer, P. (2003). "Convergence and homoplasy in the evolution of organismal form," in Origination of Organismal Form. Beyond the Gene in Developmental and Evolutionary Biology, eds G.
B. Müller and S. A. Newman (Cambridge, MA: MIT Press), 33-49.

Zakhvatkin, Y. A. (1949). The Comparative Embryology of the Low Invertebrates. Sources and Method of the Origin of Metazoan Development. Moscow: Soviet Science.

Conflict of Interest Statement: The author declares that the research was conducted in the absence of any commercial or financial relationships that could be construed as a potential conflict of interest.

Received: 31 October 2014; accepted: 10 December 2014; published online: 12 January 2015.

Citation: Minelli A (2015) Grand challenges in evolutionary developmental biology. Front. Ecol. Evol. 2:85. doi: $10.3389 /$ fevo.2014.00085

This article was submitted to Evolutionary Developmental Biology, a section of the journal Frontiers in Ecology and Evolution.

Copyright (C) 2015 Minelli. This is an open-access article distributed under the terms of the Creative Commons Attribution License (CC BY). The use, distribution or reproduction in other forums is permitted, provided the original author(s) or licensor are credited and that the original publication in this journal is cited, in accordance with accepted academic practice. No use, distribution or reproduction is permitted which does not comply with these terms. 